\title{
Anatomical femoral tunnel positioning in the medial patellofemoral ligament reconstruction: is the free-hand technique accurate?
}

\author{
Guilherme Moreira de Abreu-e-Silva ${ }^{1,2}$, Felipe Antônio Ruy Buarque ${ }^{2}$, Thiago Scherr Dias ${ }^{2}$, Pengfei Lei ${ }^{3}$, \\ Elton Luis Ribeiro Bueno ${ }^{2}$, Marco Antônio Percope de Andrade ${ }^{1}$ \\ ${ }^{1}$ Orhopaedic Department of Federal University of Minas Gerais, Belo Horizonte, Minas Gerais, Brazil; ${ }^{2}$ Felício Rocho Hospital, Belo Horizonte, \\ Minas Gerais, Brazil; ${ }^{3}$ Department of Orthopeadic Surgery, Xiangya Hospital, Central South University, Changsha, China \\ Contributions: (I) Conception and design: GM de Abreu-e-Silva, ELR Bueno, MAP de Andrade; (II) Administrative support: GM de Abreu-e-Silva, \\ MAP de Andrade; (III) Provision of study materials or patients: GM de Abreu-e-Silva, ELR Bueno; (IV) Collection and assembly of data: GM de \\ Abreu-e-Silva, MAP de Andrade, TS Dias, FAR Buarque; (V) Data analysis and interpretation: All authors; (VI) Manuscript writing: All authors; (VII) \\ Final approval of manuscript: All authors. \\ Correspondence to: Guilherme Moreira de Abreu-e-Silva. Av. do Contorno 5351, 205. Belo Horizonte, Minas Gerais, Brazil. \\ Email: guilhermeorto@gmail.com; Pengfei Lei. Department of Orthopeadic Surgery, Xiangya Hospital Central South University, Changsha, China. \\ Email: pengfeilei@csu.edu.cn.
}

Background: During medial patellofemoral ligament (MPFL) reconstruction, achieving anatomical positioning of the femoral and patellar origins is important for restoration of patellofemoral biomechanics. Although visual and manual detection can also be used to determine the femoral point of the MPFL, minimal research exists regarding accuracy of this method. Our aim was to evaluate the accuracy of free-hand method in determining the femoral point of the MPFL during surgery.

Methods: A prospective analysis was completed with 19 patients (20 knees), age ranging 15 to 39 years, in whom, three orthopedic surgeons with experience in knee procedures performed surgical reconstruction of the MPFL. MPFL femoral origin was accessed in a free-hand technique and a strict lateral view of the knee was then obtained. If the selected point was not considered appropriate, a better position was identified following the criteria set forth by Schottle.

Results: In a mean clinical follow-up of $2.3 \pm 1.3$ years, anatomical point was achieved using the free-hand palpation method in seven knees (28.5\%). Among the thirteen knees for whom the anatomical point was not attained without fluoroscopy, the mean error pattern found was $27.5 \% \pm 8.6 \%$ for proximal (P-D axis) and $24 \% \pm 6.3 \%$ for anterior in the posterior-anterior axis. The average error (difference between the marked point and the anatomical point) was $20.6 \% \pm 5.9 \%(\mathrm{P}=0.98)$ for the distal-proximal axis and $15.9 \% \pm 6.1 \%$ $(\mathrm{P}=0.77)$ for the posterior-anterior axis.

Conclusions: The anatomical palpation technique showed low accuracy, even when performed by experienced surgeons. The most common error pattern observed was proximal and anterior.

Keywords: Footprint; free-hand; ligament; patellofemoral; positioning

Submitted Nov 25, 2019. Accepted for publication Feb 21, 2020.

doi: $10.21037 /$ atm-19-3925

View this article at: http://dx.doi.org/10.21037/atm-19-3925 


\section{Introduction}

Patella dislocation accounts for $2-3 \%$ of all knee injuries (1). There are 43 cases for every 100,000 individuals (1). Instability can recur in $15-40 \%$ of patients who undergo conservative treatment after the first dislocation and increases to $49 \%$ after the second episode (2).

Medial patellofemoral ligament (MPFL), the medial retinaculum, the medial patellotibial ligament, the medial patellomeniscal ligament and the vastus medialis oblique prevent patellar lateral dislocation (3). The primary role of the MPFL in the prevention of lateral patella dislocations is well known, making many knee surgeons focus on repairing or reconstructing this structure (3-6).

Anatomically, MPFL crosses the proximal half of the medial border of the patella to the area near the medial femoral epicondyle (7). Schottle et al. (8) described radiographic criteria of MPFL femoral footprint. Anatomically, Nomura et al. (3) observed that femoral origin of the MPFL is $9.5 \mathrm{~mm}$ proximal and $5 \mathrm{~mm}$ posterior to the center of the medial epicondyle $(9,10)$.

During MPFL reconstruction, correct position of the femoral and patellar origins is crucial to restore patellofemoral biomechanics (11). Otherwise, abnormal location can increase articular pressure, potentially leading to pain and knee osteoarthritis (11). In general, surgeons use the visualization and palpation (free-hand technique) of medial structures (i.e. medial epicondyle, adductor tubercle and medial gastrocnemius tubercle) as reference for determining the proper femoral tunnel location. Although visual and manual methods can decrease operative time, few researches exist regarding quantification of the accuracy in this method. Even though, fluoroscopy is not uniformly adopted by knee surgeons to check accuracy in MPFL reconstructions.

The aim of this study was to evaluate the accuracy of free-hand method to determine MPFL femoral location during surgery and describe its accuracy comparing with fluoroscopic references (8).

\section{Methods}

A prospective analysis was completed with 19 patients (20 knees), age ranging 15 to 39 years, in whom, two orthopedic surgeons with experience in knee surgery performed surgical reconstructions of the MPFL. This study was previously approved by ethical committee at our Institution (approval number CAAE-52885316.1.0000.5125).

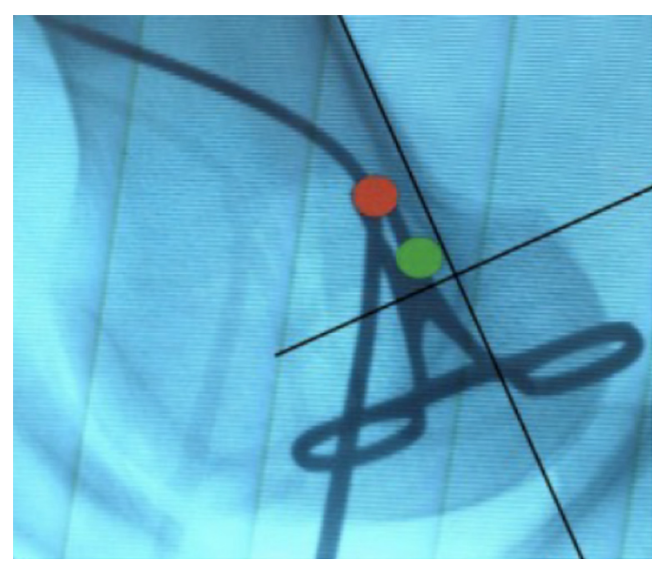

Figure 1 Evaluation of the femoral attachment points determined using the free-hand technique (red point) and the Schottle technique (green point).

MPFL femoral origin was accessed in a free-hand technique in a point posterior and proximal to the medial epicondyle and distal to the adductor tubercle. After that, a Kirschner wire $(2.0 \mathrm{~mm})$ was inserted according with surgeon's perception. A strict lateral view of the knee was then obtained. If the selected point was not considered appropriate, a better position was identified following the fluoroscopic criteria. A Kocher's clamp was used to determine the entry point of Kirschner wire during fluoroscopy (Figure 1). The selected point was considered appropriate according with surgeon decision. Mean clinical follow-up period was $2.3 \pm 1.3$ years in this cohort.

In this present study, we proposed a quadrant method using Cartesian coordinate system to quantify error, with the Y-axis corresponding to a distal-proximal orientation and the $\mathrm{X}$-axis corresponding to a posterior-anterior orientation (Figure 2). In each case, a grid was plotted using computer software $\left(\right.$ Osirix $\left.^{\circledR}\right)$ in the metaphyseal and epiphyseal regions of the strict lateral fluoroscopy image of the knee. The posterior boundary coincided with the posterior cortex of the femoral shaft. Meanwhile, the upper boundary coincided anteriorly with the proximal metaphyseal femoral starting point (where the anterior cortical becomes thinner) and inferiorly with the line perpendicular to the posterior cortex of the femur that runs tangent to the posterior boundary of the Blumensaat line (Figure 2). When the surgically marked point was below the distal limit of the quadrant, the spread image was projected distally to the inferior limit of the quadrant, while negative values were given to the coordinates. 

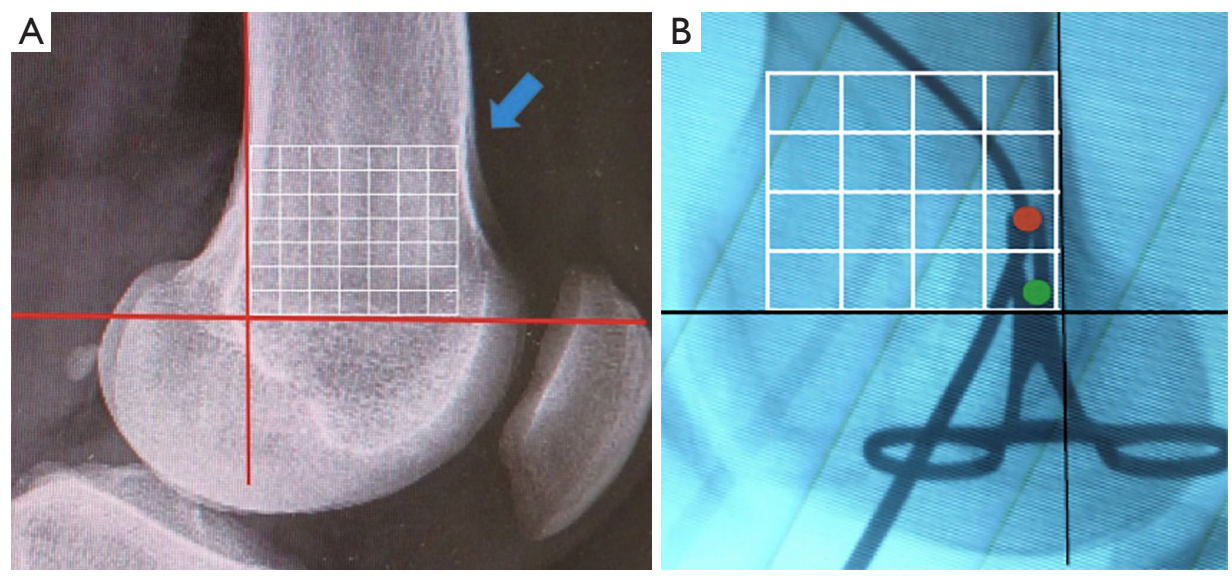

Figure 2 Quadrant-based error quantification system for the marking the femoral fixation point in the MPFL reconstruction. Radiography showing quadrant method (left) and fluoroscopy image showing free-hand technique point (red mark) and Schottle's point (green mark) with the quadrant applied (right). Quadrant limits description: posterior femoral cortex (posterior), orthogonal line beginning in the posterior Blumensaat line intersection to the posterior femoral cortex line (distal) and thickening of the anterior femoral cortex (anterior: blue arrow). MPFL, medial patellofemoral ligament.

The distance in the $\mathrm{X}$ - and Y-planes between the anatomic point and the one determined by the free-hand technique was then calculated (Osirix ${ }^{\circledR}$ Software). These results were expressed as a percentage in order to avoid the effect of different magnifications in the attained images. The anatomic point (i.e., Schottle's point) was found to be at $8.7 \% \pm 1.1 \%$ for the distal-proximal axis $(\mathrm{Y})$ and at $7.2 \% \pm 1.5 \%$ for the posterior-anterior axis $(\mathrm{X})$.

Statistical analyses were completed to evaluate, the Cartesian findings described above. Quantitative variables were analyzed using ANOVA test owing to their parametric distribution (Kolmogorov-Smirnov test).

\section{Results}

In total, 6 men and 13 women underwent the operation, with an average age of 25.1 years (ranging from 15 to 39 years). Of these, seven patients reported more than 10 episodes of dislocation of the patella (Table 1). In addition, the right side was more affected (ten patients). Of the 20 surgical procedures, thirteen MPFL isolated reconstruction were done, while seven knees required additional distal realignment. Preoperative mean (SD) Kujala score was $62.9 \pm 1.9$. The mean clinical follow-up was $2.3 \pm 1.3$ years in this cohort (Table 2).

In only seven procedures $(28.5 \%)$, the anatomical point was achieved using the free-hand palpation method. Among the knees in which the Schottle's point was not obtained without fluoroscopy, the mean error location was $27.5 \% \pm 8.6 \%$ for the distal-proximal axis and $24 \% \pm 6.3 \%$ for the posterior-anterior axis. The average error (difference between free-hand's point and Schottle's point) was $20.6 \% \pm 5.9 \%(\mathrm{P}=0.98)$ for the distal-proximal axis and $15.9 \% \pm 6.1 \%(\mathrm{P}=0.77)$ for the posterior-anterior axis. Improvement in clinical terms was attained in all patients, with a postoperative Kujala score of $87.4 \pm 1.8$ points (Table 3).

\section{Discussion}

More than 100 surgical procedures have been already described for acute or chronic patellofemoral instability treatment (12). The role of MPFL reconstruction in patella instability treatment has been extensively demonstrated and tested $(11,13,14)$. Reproducing MPFL anatomy and biomechanical is essential in restoring patellar stability and preventing complications $(15,16)$. In this study, we observed the importance of radiological evaluation in MPFL femoral footprint location.

Even in cases of experience surgeons performing MPFL reconstruction procedures, the femoral fixation point was only found in seven knees $(28.5 \%)$ using the free-hand technique. The use of fluoroscopy was associated with a change in the position of the femoral guide wire in $72.5 \%$ of the procedures, indicating low accuracy of free-hand technique for determining the anatomical MPFL femoral location. 
Page 4 of 7 de Abreu-e-Silva et al. Anatomical femoral tunnel positioning in the MPFL reconstruction: free-hand technique accuracy

Table 1 Demographic: surgery type, anatomical palpation results, surgeon, standard error, and complications for the patients evaluated in this study

\begin{tabular}{|c|c|c|c|c|c|c|c|c|c|}
\hline Patient & Gender & Age & $\begin{array}{l}\text { Number of } \\
\text { dislocations }\end{array}$ & Side & $\begin{array}{l}\text { Procedure } \\
\text { undertaken }\end{array}$ & $\begin{array}{l}\text { Free hand attained } \\
\text { anatomical point? }\end{array}$ & Surgeon & $\begin{array}{l}\text { Error } \\
\text { pattern }\end{array}$ & Complications $^{\star}$ \\
\hline GBS & M & 17 & 2 & $\mathrm{R}$ & MPFL & No & GMAS & $P+A$ & \\
\hline MCS & $\mathrm{F}$ & 21 & $>10$ & L & MPFL + DIST. TAT & Yes & GMAS & - & \\
\hline ICF & $\mathrm{F}$ & 15 & $>10$ & L & MPFL + DIST. TAT & No & ELB & $P+A$ & Manipulation-week 11 \\
\hline EHR & $\mathrm{F}$ & 27 & 4 & L & MPFL & Yes & GMAS & - & \\
\hline RARM & $\mathrm{F}$ & 32 & $>10$ & $\mathrm{R}$ & MPFL & No & GMAS & $P+A$ & \\
\hline CRS & M & 28 & $>10$ & $\mathrm{R}$ & MPFL & No & GMAS & $P+A$ & \\
\hline PMPC & $\mathrm{F}$ & 31 & 2 & L & MPFL & No & GMAS & $P+A$ & \\
\hline FGSL & $\mathrm{F}$ & 25 & 3 & $\mathrm{R}$ & MPFL + DIST. TAT & No & GMAS & $D+A$ & \\
\hline MGSG & M & 16 & 10 & L & MPFL & No & GMAS & $P+A$ & \\
\hline RPS & $\mathrm{F}$ & 22 & 10 & $\mathrm{R}$ & MPFL + DIST. TAT & No & GMAS & $P+A$ & Manipulation-week 12 \\
\hline EXM & M & 39 & $>10$ & $\mathrm{R}$ & MPFL + DIST. TAT & Yes & GMAS & - & \\
\hline LCS & $\mathrm{F}$ & 33 & $>10$ & L & MPFL + DIST. TAT & Yes & GMAS & - & \\
\hline LCS & $\mathrm{F}$ & 33 & $>10$ & $\mathrm{R}$ & MPFL + DIST. TAT & Yes & GMAS & - & \\
\hline EEA & $\mathrm{F}$ & 28 & 3 & L & MPFL & No & GMAS & $P+A$ & \\
\hline GGDA & $\mathrm{F}$ & 23 & 4 & $\mathrm{R}$ & MPFL & No & GMAS & $P+A$ & \\
\hline AAD & $\mathrm{F}$ & 23 & 4 & $\mathrm{R}$ & MPFL & No & GMAS & $P+A$ & \\
\hline MAP & M & 25 & 3 & L & MPFL & Yes & GMAS & - & \\
\hline FMA & $\mathrm{F}$ & 26 & 6 & L & MPFL & No & GMAS & $P+A$ & \\
\hline RLA & $\mathrm{F}$ & 19 & 3 & L & MPFL & Yes & GMAS & - & \\
\hline GGL & M & 20 & 2 & $\mathrm{R}$ & MPFL & No & GMAS & $P+A$ & \\
\hline
\end{tabular}

*, two patients underwent manipulation of the knee under anesthesia and developed arthrofibrosis between weeks 11 and 12 . There was no evidence of infection, additional patellofemoral dislocation, anterior knee pain, patellar fracture, or other surgical complication. $\mathrm{M}$, male; $\mathrm{F}$, female. R, right; L, left; MPFL, medial patellofemoral ligament; P, proximal; D, distal; A, anterior.

Patellofemoral articulation biomechanics are influenced by femoral tunnel positioning after MPFL reconstruction (17). The proximal positioning error increases contact and pressure over the medial facet, what can lead to early osteoarthritis and pain after surgery $(18,19)$. Moreover, proximal positioning error of $5 \mathrm{~mm}$ or an addition of $10 \mathrm{~N}$ graft tension could significantly increase medial facet of the patella by more than $50 \%$ (12). Distal placement can lead to graft looseness and, ultimately, failure to stabilize the patella (19). Incorrect positioning in the frontal plane (either proximal or distal) has a major influence on graft isometry, while anterior-posterior error is more tolerated (17).

The radiographic location of the femoral fixation point in MPFL reconstruction has been proposed $(17,20)$. Correct positioning through free-hand technique remains a challenge, with error rates above $70 \%$ as demonstrated in the present study. Knee position during fluoroscopy can also affect visualization of the anatomical point. Balcarek et al. (20) showed that a difference of $5^{\circ}$ in knee rotation during lateral image acquisition could result in a $5 \mathrm{~mm}$ deviation from the femoral footprint.

The average errors of $20.6 \% \pm 5.9 \%(\mathrm{P}=0.98)$ for the distal-proximal axis and $15.9 \% \pm 6.1 \%(\mathrm{P}=0.77)$ for the posterior-anterior axis, respectively, demonstrate a significant topographic difference regarding Schottle's point. Although this study has not found a statistically significance between these points, thirteen patients required repositioning of the femoral guide wire, which represents an important change decision during perioperative time.

Servien et al. (19) observed that proximal misplacement 
Table 2 Clinical and surgical results

\begin{tabular}{|c|c|c|c|c|c|c|c|c|c|}
\hline Patient & Side & $\begin{array}{l}\text { Procedure } \\
\text { undertaken }\end{array}$ & $\begin{array}{l}\text { Preoperative } \\
\text { Kujala score }\end{array}$ & $\begin{array}{l}\text { Postoperative } \\
\text { Kujala score }\end{array}$ & $\begin{array}{c}\text { Postoperative } \\
\text { and preoperative } \\
\text { Kujala score } \\
\text { difference }(\Delta)^{*}\end{array}$ & $\begin{array}{l}\text { Free hand } \\
\text { attained } \\
\text { anatomical } \\
\text { point? }\end{array}$ & Surgeon & $\begin{array}{c}\text { Error } \\
\text { pattern }\end{array}$ & Complications* \\
\hline GBS & $\mathrm{R}$ & MPFL & 61 & 84 & 23 & No & GMAS & $P+A$ & \\
\hline MCS & L & MPFL + DIST. TAT & 58 & 86 & 32 & Yes & GMAS & - & \\
\hline EHR & L & MPFL & 61 & 92 & 31 & Yes & GMAS & - & \\
\hline RARM & $\mathrm{R}$ & MPFL & 57 & 86 & 29 & No & GMAS & $P+A$ & \\
\hline CRS & $\mathrm{R}$ & MPFL & 62 & 82 & 20 & No & ELB & $P+A$ & \\
\hline RPS & $\mathrm{R}$ & MPFL + DIST. TAT & 61 & 92 & 31 & No & ELB & $P+A$ & $\begin{array}{c}\text { Manipulation-week } \\
12\end{array}$ \\
\hline EXM & $\mathrm{R}$ & MPFL + DIST. TAT & 70 & 94 & 24 & Yes & GMAS & - & \\
\hline LCS & L & MPFL + DIST. TAT & 65 & 94 & 29 & Yes & GMAS & - & \\
\hline LCS & $\mathrm{R}$ & MPFL + DIST. TAT & 62 & 83 & 21 & Yes & GMAS & - & \\
\hline EEA & L & MPFL & 66 & 82 & 16 & No & GMAS & $P+A$ & \\
\hline GGDA & $\mathrm{R}$ & MPFL & 59 & 86 & 27 & No & GMAS & $P+A$ & \\
\hline
\end{tabular}

$(\Delta)^{\star} P$ value $=0.41-$ ANOVA test.

was more common than anterior mal position. In this work, we found a trending pattern in misplacement occurring toward anterior and proximal to the MPFL footprint. Distal misplacement occurred just once, and no point was positioned more posterior than ideal. This may occur because of proximity of medial osseous landmarks (medial epicondyle, adductor tubercle and gastrocnemius tubercle).

The quadrant method to quantify the femoral MPFL location can suffer some imprecision during its measurement and must be addressed as a potential limitation of the study. Although the posterior cortex and Blumensaat's line are objective landmarks to the quadrant method, the anterior and superior limit can suffer some degree of subjectivity.
Other potential study limitation is the use of bidimensional image acquiring method, i.e., fluoroscopy, which can suffer interference according with limb position during exam. Methods with 3D-image as computed tomography can minimize this potential flaw, however, fluoroscopy is still the most available method during perioperative scenario.

The anatomical palpation technique showed low accuracy, even when performed by experienced surgeons, as shown by the need of reposition the guide wires in $72.5 \%$ of cases. The most common pattern of error observed was proximal and anterior misplacement. Fluoroscopy was fundamental in determining the anatomical femoral fixation point for MPFL ligament reconstruction. 
Page 6 of 7 de Abreu-e-Silva et al. Anatomical femoral tunnel positioning in the MPFL reconstruction: free-hand technique accuracy

Table 3 Error quantification (\%) for the femoral fixation point in MPFL reconstruction using anatomical palpation

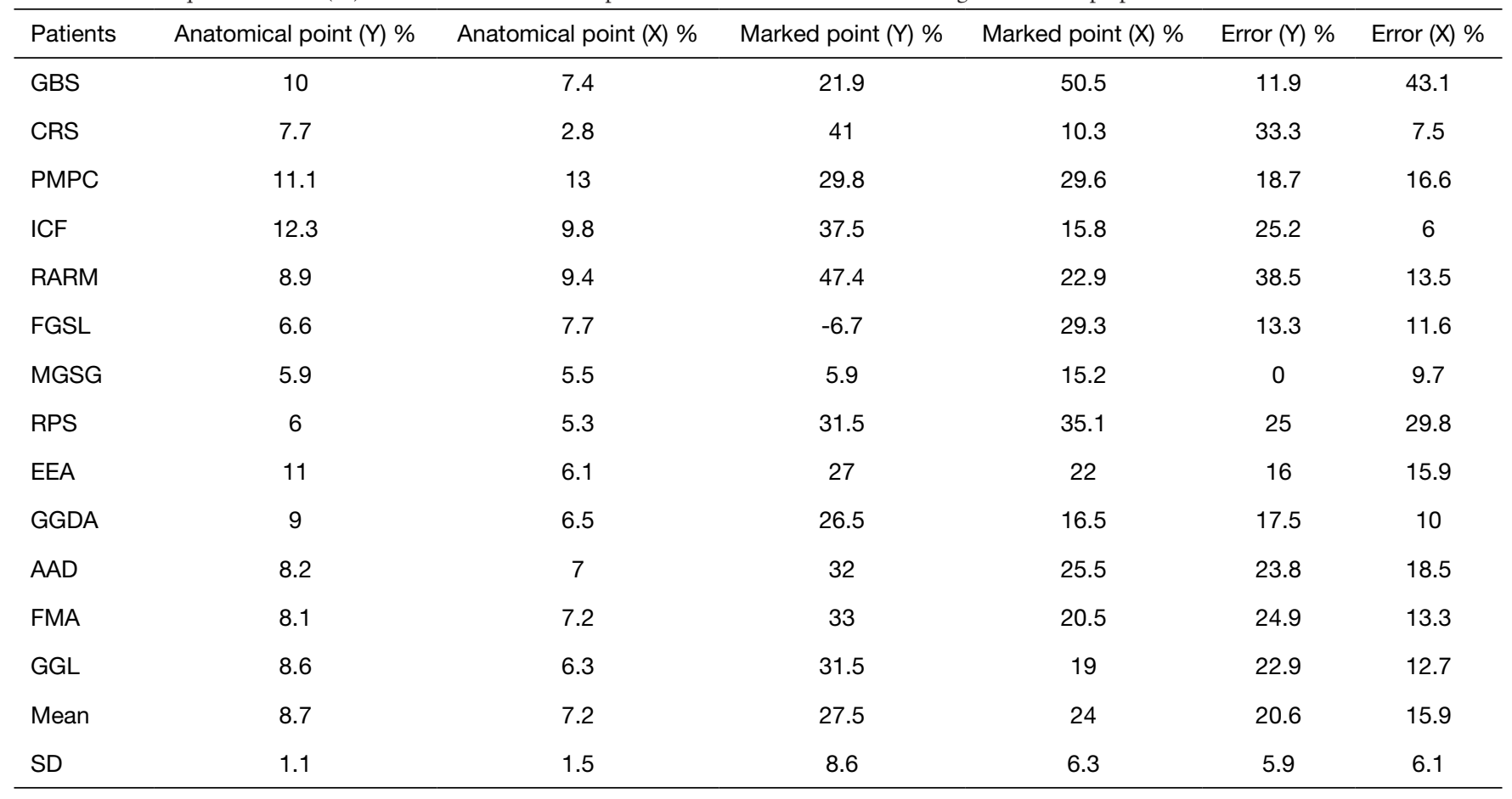

The anatomical point corresponds to the Schottle point studied using the quadrant method over two coordinate ranges (Y: distal/proximal and $\mathrm{X}$ : posterior/anterior). The marked point corresponds to the point that was determined using the anatomical palpation (free-hand) method. The error corresponds to the arithmetic difference between the two points.

\section{Acknowledgments}

Funding: None.

\section{Footnote}

Data Sharing Statement: Available at http://dx.doi. org/10.21037/atm-19-3925

Conflicts of Interest: All authors have completed the ICMJE uniform disclosure form (available at http://dx.doi. org/10.21037/atm-19-3925). The authors have no conflicts of interest to declare.

Ethical Statement: The authors are accountable for all aspects of the work in ensuring that questions related to the accuracy or integrity of any part of the work are appropriately investigated and resolved. The patient gave an informed consent before taking part. The study was conducted in accordance with the Declaration of Helsinki (as revised in 2013). This study was previously approved by ethical committee at our Institution (approval number
CAAE-52885316.1.0000.5125).

Open Access Statement: This is an Open Access article distributed in accordance with the Creative Commons Attribution-NonCommercial-NoDerivs 4.0 International License (CC BY-NC-ND 4.0), which permits the noncommercial replication and distribution of the article with the strict proviso that no changes or edits are made and the original work is properly cited (including links to both the formal publication through the relevant DOI and the license). See: https://creativecommons.org/licenses/by-nc-nd/4.0/.

\section{References}

1. Sillanpää P, Mattila VM, Iivonen T, et al. Incidence and risk factors of acute traumatic primary patellar dislocation. Med Sci Sports Exerc 2008;40:606-11.

2. Stefancin JJ, Parker RD. First time traumatic patellar dislocation: a systematic review. Clin Orthop Relat Res 2007;455:93-101.

3. Nomura E, Inoue M, Osada N. Anatomical analysis of the medial patellofemoral ligament of the knee, especially the 
femoral attachment. Knee Surg Sports Traumatol Arthrosc 2005;13:510-5.

4. Conlan T, Garth WP, Lemons JE. Evaluation of the medial soft tissue restraints of the extensor mechanism of the knee. J Bone Joint Surg Am 1993;75:682-93.

5. Hautamaa PV, Fithian DC, Kaufmann KR et al. Medial soft tissue restraints in lateral patellar instability and repair. Clin Orthop 1998;349:174-82.

6. Nomura E, Horiuchi Y, Kihara M. Medial patellofemoral ligament restraint in lateral patellar translation and reconstruction. Knee 2000;7:121-7.

7. Amis AA. Current concepts on anatomy and biomechanics of patellar stability. Sports Med Arthrosc Rev 2007;15:48-56.

8. Schöttle PB, Schmeling A, Rosenstiel N, et al. Radiographic landmarks for femoral tunnel placement in medial patellofemoral ligament reconstruction. Am J Sports Med 2007;35:801-4.

9. Nomura E, Fujikawa K, Takeda T, et al. Anatomical study of the medial patellofemoral ligament (in Japanese). Bessatsu Seikeigeka 1992;22:2-5.

10. Smirk C, Morris H. The anatomy and reconstruction of the medial patellofemoral ligament. Knee 2003;10:221-7.

11. Reagan J, Kullar R, Burks R. MPFL Reconstruction technique and results. Orthop Clin North Am 2015;46:159-69.

12. Koh JL, Stewart C. Patellar instability. Orthop Clin North Am 2015;46:147-57.

13. Previtali D, Roumenov SM, Pagliazzi G, et al. Recurrent patellar dislocations without untreated predisposing factors: MPFL reconstruction vs other medial soft tissue

Cite this article as: de Abreu-e-Silva GM, Buarque FAR, Dias TS, Lei P, Bueno ELR, de Andrade MAP. Anatomical femoral tunnel positioning in the medial patellofemoral ligament reconstruction: is the free-hand technique accurate? Ann Transl Med 2020;8(15):924. doi: 10.21037/atm-19-3925 surgical techniques - A meta-analysis. Arthroscopy 2020;36:1725-34.

14. Holliday CL, Hiemstra LA, Kerslake S, et al. Relationship between Anatomical Risk Factors, Articular Cartilage Lesions, and Patient Outcomes Following Medial Patellofemoral Ligament Reconstruction. Cartilage 2019:1947603519894728.

15. Redfern J, Kamath G, Burks R. Anatomical confirmation of the use of radiographic landmarks in medial patellofemoral ligament reconstruction. Am J Sports Med 2010;38:293.

16. Duchman KR, DeVries N, McCarthy M, et al. Biomechanical evaluation of medial patellofemoral ligament reconstruction. Iowa Orthop J 2013;33:64-9.

17. Stephen JM, Kaider D, Lumpaopong P, et al. The effect of femoral tunnel position and graft tension on patellar contact mechanics and kinematics after medial patellofemoral ligament reconstruction. Am J Sports Med 2014;42:364.

18. Elias JJ, Cosgarea A. Technical errors during medial patellofemoral ligament reconstruction could overload medial patellofemoral Cartilage. Am J Sports Med 2006;34:1478-85.

19. Servien E, Fritsch B, Lustig S, et al. In vivo positioning analysis of medial patellofemoral ligament reconstruction. Am J Sports Med 2011;39:134.

20. Balcarek P, Walde T. Accuracy of femoral tunnel placement in medial patellofemoral ligament reconstruction: The effect of a nearly true-lateral fluoroscopic view. Am J Sports Med 2015;43:2228-32. 